\title{
Entre el amor y el desamparo. Historia de la infancia en México, siglo XVIII-XX
}

\section{Leonardo Chávez Miranda}

Centro de Investigaciones y Estudios Superiores en Antropología Social

Unidad Regional Peninsular, México

leonardochavez85@gmail.com

María de Lourdes Herrera Feria y Zoila Santiago Antonio (editoras), Entre el amor y el desamparo. Historia de la infancia en México, siglos XVIII-XX, Puebla, Ediciones del Lirio, 2019 .

La historiografía de la infancia en México se ha nutrido de diversas investigaciones que han problematizado en el ámbito educativo, laboral, judicial, así como en el amparo social. La escasez de documentales sobre las diversas experiencias de los niños ha limitado conocer a fondo sobre la etapa que todo ser humano ha transitado, esto ha sido uno de los obstáculos en la historia de los infantes. Sin embargo, esto no ha sido impedimento para que surja el interés en la historiografía de la infancia para problematizar en la multiplicidad y complejidades sociales, culturales y educativas. La obra colectiva que reseñamos, coordinada por las Dras. Lourdes Herrera Feria y Zoila Santiago Antonio, titulada Entre el amor y el desamparo. Historia de la infancia en México, siglo XVIII-XX, es una invitación a reflexionar sobre la primera etapa que todo ser humano experimenta, ya sea en el hogar, la

\section{(c) () (9)} No-Comercial 4.0 Internacional.

Secuencia. E-ISSN 2395-8464 http://secuencia.mora.edu.mx/

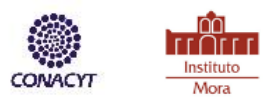


escuela, en los centros laborales y en otros casos en los centros de reclusión como víctimas o victimarios. Los once textos que componen el libro a través de diversas fuentes documentales y enfoques rescatan las singularidades de los infantes en los variados espacios y ámbitos socioculturales. A través de distintas propuestas teóricas y metodológicas contribuyen a la historia de la infancia en México posicionando a los niños como el eje central de la investigación.

El libro esta estructurado de forma cronológica, en conjunto presentan tres tendencias centrales: las instituciones establecidas para el cuidado y control de los infantes, los establecimientos correccionales en los cuales se incluyen algunos de los procesos judiciales, así como la niñez en sus prácticas cotidianas. Los autores, a partir de los indicios encontrados en las fuentes documentales, abordan el abandono, la formación educativa, la delincuencia, los juegos, la protección de los infantes, así como la revisión de fuentes judiciales que revelan pasajes oscuros de la vida de los infantes. Los investigadores han puesto énfasis en recrear la situación de los niños en las prácticas más comunes, logrando desentrañar que las etapas más significativas del ser humano confluyen entre el amor y el desamparo.

Edgar Zuno, en su artículo "Los niños expósitos en la ciudad de Valladolid de Michoacán durante la segunda mitad del siglo XVIII”, a partir de las fuentes parroquiales reconstruye el alto grado de abandono que sufrieron algunos infantes a causa de la ilegitimidad y la pobreza. El autor señala que el hospicio fue uno de los mecanismos por el cual se trató de solucionar el problema que representaba el aumento de niños expósitos. Solución que se vio reforzada a partir de que el hospicio se diera a la tarea de dar en 
adopción a los infantes con las familias que proporcionan lo necesario, así como educarlos en la fe cristiana.

El artículo de Rosario Torres y Juan Leonel Rendón, titulado "La idea de la 'utilidad común’ en la enseñanza de las primeras letras a los niños poblanos durante el siglo XIX”, muestran la difusión de los valores de la ilustración en el establecimiento creado por la Junta de Caridad en 1813, donde se enseñaban a los niños y niñas las primeras letras. A partir del reglamento de la escuela ilustran el objetivo de formar a los individuos que contribuirían al progreso y el mejoramiento social, sin descuidar la enseñanza religiosa. El espacio educativo se convirtió en el laboratorio que trataría de formar a los niños en práctica y la capacitación, para que fueran útiles a la sociedad.

El artículo de Lourdes Herrera y Evelyn Sanchez denominado "La infancia constituida desde la práctica legal y médica en el valle de Puebla-Tlaxcala, 1802-1943”, reconstruyen parte del entorno familiar, la enseñanza o crianza y la concepción de infancia en el ámbito jurídico y clínico, todo ello a partir de los indicios que proporcionan los expedientes judiciales. Las autoras realizaron un escrupuloso análisis de los diversos expedientes con lo que muestran la vida rígida y en ocasiones deplorable de los infantes, tanto en las prácticas de sociabilización dentro del seno familiar como los atroces actos cometido sobre ellos.

En cuanto al texto de Jorge Alberto Trujillo Bretón llamado "Macedonio Velásquez o un primer indicio para estudiar a la niñez delincuente en Jalisco en la primera mitad del siglo XIX”. Aborda a los niños que cometieron algún hecho delictivo y que fueron procesados como adultos, durante el periodo de 1888 a 1911. En un contexto modernista pero riguroso, donde se pretendía perseguir y castigar a aquellos niños que estuvieran fuera de la norma. En Secuencia. E-ISSN 2395-8464 
los diversos casos que presenta el autor los delitos más comunes fueron por robo y lesiones y en otros casos por el infortunio de encontrarse en el lugar equivocado. El autor sostiene que la sociedad jalisciense porfiriana, no dudo en tratar a los niños delincuentes como pequeños adultos, por lo que se aplicó los mismos castigos.

El artículo de María Sánchez Calleja, denominado "Proyecto educativo para educandos y corrigendos en el segundo imperio mexicano", presenta el plan formativo diseñado para formar a los niños, niñas y jóvenes de las instituciones de la beneficencia imperial. Las autoridades imperiales estaban preocupadas por el descuido de la instrucción de los menores que estaba en calidad de depositados o internados. Por lo que el objetivo de la autora es explicar cuál fue la propuesta educativa que trató de caracterizar a un ideal de infancia adscrita a la Beneficencia Pública en el segundo imperio mexicano. El proyecto educativo también contemplaba la remodelación de los distintos edificios que controlaba la beneficencia, además de asilar, alimentar y dar techo, su principal objetivo era educar para la vida social. Sin duda, el proyecto educativo imperial esperaba formar a los menores internos en sujetos trabajadores, sumisos y disciplinados. El ideal de infancia proyectado fue que los niños menesterosos y los que perdían el tiempo fueran productivos a la sociedad. Un proyecto ambicioso que no solo esperaba una retribución a la sociedad sino reducir a mediano plazo el costo de manutención.

Delia Salazar Anaya en su texto "Las infancias: entre la memoria y el olvido de los juegos y el entrenamiento”, aborda las diversiones y los juegos en los que participaron algunos niños y niñas en diferentes espacios del territorio mexicano en las últimas décadas del siglo XIX y principios del XX. A través de un corpus documental compuesto por 
memorias familiares, autobiografías y diarios, analiza el discurso directo e indirecto de las prácticas cotidianas de los infantes. La autora recrea los contextos a partir de los recuerdos de los autores anónimos que aluden a las fiestas, la música, los juegos y los confites que gozaban cuando eran niños. Se materializa las formas de la cultura popular de la sociedad.

David Guerrero Flores aborda el tema del trabajo infantil en México a principios del siglo XX hasta nuestros días. Analiza las continuidades y los cambios sobre el trabajo infantil, así mismo reflexiona sobre el panorama internacional y nacional contemporáneo. Con base en documentos de archivo, entrevistas, información estadística señala que hay múltiples factores que han propiciado la incursión de las niñas, niños y adolescentes en áreas productivas. El autor señala que el trabajo infantil ha tenido una práctica constante, ya sea dentro del seno familiar en donde se aprovecha de los beneficios que proporciona la niña, niño o adolescente para la subsistencia del hogar o como una opción formativa que deriva en la explotación del trabajo desempeñado por los menores de edad. El autor presenta un panorama poco alentador en el ámbito internacional y nacional, puesto que los infantes ocupan un índice alto dentro de las actividades laborales.

En el texto de Oscar Reyes aborda las experiencias de enamoramiento y pasión de los infantes en una sociedad tapatía a principios del siglo XX, en una sociedad donde los códigos de moralidad imperaban. Para ello, el autor recurre a diversas autobiografías y memorias que dan cuenta de ciertas situaciones de enamoramiento que experimentaron. El autor toma como caso particular la obra de Agustín Yáñez, como fuente principal le permite conocer aspectos sociales y culturales del contexto donde se desarrolló parte de su infancia, entre amigos, parientes y en especial cortejando al sexo opuesto. 
Hubonor Ayala analiza los discursos oficiales como privados, para reconstruir el objetivo del gobierno y la sociedad posrevolucionaria, la creación de una nueva generación de ciudadanos, saludable, trabajadora, educada y políticamente obediente. A partir de la revisión de diversos acervos documentales, aborda la protección de la maternidad y la primera infancia en el estado de Veracruz durante las décadas de los años veinte y treinta del siglo pasado. El autor se interna en las acciones que se implementaron para asistir y brindar los servicios de salud englobado en la acción de "protección a la infancia". Estas acciones fueron el efecto del radicalismo posrevolucionario propuesto por Adalberto Tejeda que se concretaron en diversos programas de educación y salubridad pública. Señala Hubonor que hubo una continuidad en los esfuerzos por la protección a la infancia y maternidad, por tanto, la implementación de programas como Pro-Infancia y la Gota de Leche en el estado de Veracruz, sumaron esfuerzos para la protección de un sector importante para "el futuro" de la nación: los niños.

En cuanto al trabajo de Zoila Santiago titulado "El tribunal para menores del Distrito Federal, extensión familiar para la corrección e integración social, 1920-1930”. La autora analiza la simbiosis que se creó entre las familias y el Tribunal de Menores para la formación de los "nuevos" ciudadanos, durante las décadas de los veinte y los treinta del siglo XX. A partir de la revisión minuciosa de los expedientes judiciales del tribunal, presenta los diversos problemas que enfrentaban los menores infractores dentro del seno familiar como fuera de él. El contexto donde se desarrollaron los menores infractores fue tema de discusión ligada a la familia. Por lo que, la autora señala que el discurso de los reformadores sociales posrevolucionario daba un papel central a la familia en la formación de los ciudadanos, sin embargo, abundaban los prejuicios sobre las clases pobres. Señala la autora que el creciente Secuencia. E-ISSN 2395-8464 
interés del Estado por los niños permitió la intromisión en las familias de los sectores populares, por lo que los debates giraron en el papel de la familia para prevenir o ser causante de la delincuencia infantil.

Por último, el trabajo de María Teresita Hernández, titulado "Una aproximación a la historia de la infancia a partir de las fuentes judiciales” realiza un análisis sobre las diversas fuentes judiciales disponibles en el estado de Tlaxcala, donde se encuentran indicios de los infantes en incomparables situaciones. A partir de la revisión de los diversos expedientes de tipo criminal, la autora presenta los testimonios de los niños en diversas situaciones, ya sea como infractores o como víctimas. A partir de diversas preguntas, la autora rescata cuatro expedientes de distintos años que dan cuenta de las voces directas o indirectas de los infantes. Los casos presentados invitan a reflexionar en los posibles temas que ponen como sujeto principal al infante. Por lo que el análisis de los expedientes judiciales revela la multiplicidad de infancias vividas a lo largo del tiempo, con fortunas o desventuras. El trabajo invita a reflexionar sobre el papel central del infante dentro de los expedientes judiciales. 